\title{
The Current State of Management Development in Iran: Case of Insurance Industry
}

\author{
Nastaran SimarAsl ${ }^{1}$, Ali Attafar ${ }^{1}$, Arash Shahin ${ }^{1}$, Hooshang Talebi ${ }^{2}$ \\ ${ }^{1}$ Department of Administrative Sciences and Economics University of Isfahan \\ Email: n.simar@utk.edu, attafar@yahoo.com, arashshahin@htmail.com \\ ${ }^{2}$ Department of Sciences University of Isfahan \\ Email: H-talebi@sci.ui.ac.ir
}

\begin{abstract}
The aim of this paper is to assess the current state of management development (MD) in insurance industry of Iran in terms of managerial and organizational characteristics, human resource management strategies, training system and management skills. Drawing upon survey data, findings show that insurance companies in Iran score lower than average in all the above-mentioned factors. Also no significant difference is found in terms of insurance managers' views regarding the current status of managerial and organizational characteristics, human resource management strategies, training system and management skills among managers of different organizational levels. Also, managers' motivation to learn and HRM strategies accounted for the most variance in managerial skills.
\end{abstract}

Keywords: Management development, Training, Human resource strategies, Insurance industry, Iran.

\section{Introduction}

Future business leaders and managers as pillars of organizational competitiveness need to master a complicated combination of various skills to excel [1]. Although no unique approach is pursued by MD scholars [2], there is a consensus among human resource development scholars that MD plays a strategic role in organizations [3]. Also, in the absence of MD, organizations lack flexibility in response to environmental changes and national economies fail to maintain their competitiveness [4]. 
MD activities and initiatives are heavily dependent on the rise and fall of the national economy [5]. Recently, economic sanctions being imposed on Iran has significantly impacted financial industries including insurance industry. Also, the extensive privatization of insurance industry has changed many of the business practices in this industry. Thus, insurance industry faces increasing challenges in terms of both maintaining and increasing competitiveness. These challenges are expected to change not only the skills required but also the incentives of individuals and employers to invest in management training and development [6]. In other words, the fundamental changes mentioned above contribute to driving new roles and responsibilities for managers at different organizational levels stemming from shorter life cycle of managerial skills and competencies [1].

Previous research shows that there is inconsistency between what managers believe about MD practices and what actually happens in organizations [7]. Also, there is dearth of empirical research on MD [8], the majority of which has been conducted in Western countries [9], [10], [5]. Therefore, reaching a real understanding about MD practices requires taking into account the national and institutional context of countries [11]. In addition, previous research does not delve into MD differences in terms of industry characteristics [12]. To address these gaps in previous research, this paper seeks to solicit the views of managers who are the integral part of MD attempts about various aspects of MD in insurance companies in Iran.

For managers operating in countries experiencing similar conditions to Iran, the results should be relevant. In terms of the scope of our study, it encompasses a wide range of management development dimensions including managers' knowledge and experience, their level of motivation, organizational resources devoted to management development initiatives in insurance companies, human resource strategies and training systems in organizations and managers' developed skills. Findings of this research have potential impact on the design and implementation of learning initiatives in industry and corporate contexts.

The remainder of this paper is structured as follows: The next section focuses on literature review. Next, research methodology and research findings are presented. The last section concludes the paper and draws some avenues for future research.

\section{Literature Review}

Increasingly, organizations are viewing the development of their managers as a key priority which is indicative of their concern for management population [4]. MD has been defined as a complex process in which individuals are provided with learning opportunities to perform effectively in managerial roles [13]. Not all MD activities happen inside the organization boundaries [14]; thus, MD interacts with environmental and other organizational factors and integrates with other 
organizational processes and procedures. MD as a multi-faceted phenomenon is contingent on individuals' needs and abilities and organizational context [12]. Traditionally, organizations were assumed as closed systems with static and homogeneous workforce where value creation was a purely internal process. This mindset is gradually being replaced by a new one in which organizations are viewed as open systems in which value creation is based on knowledge distribution and intangible assets including managerial assets [1].

There is little consensus among scholars on the domains of MD [12]. Training and development are concerned with developing the capacity of managers to achieve defined objectives [7]. In addition, findings of previous research demonstrate that organizations are adopting a systems perspective in managing their MD initiatives and activities, the majority viewing $\mathrm{MD}$ as an integral part of a wider organizational system [4]. Therefore, MD is not a single activity or does not comprise of separate independent activities; thus, it heavily relies on the interactions of individual and organizational characteristics [15], [16].

Previous research shows that firms increasingly try to experiment with several MD activities to handle the increased environmental complexity [7]. For example, Raybould and Wilkins (2005) have concluded that in hospitality industry the increased competition in industry has changed the importance and priority of managers' skills. In this regard, recent scholarly attempts have called the academia's attention to take into account more contextual complexities including managers' needs and backgrounds, etc [12]. In a research conducted among Norwegian companies, it was revealed that managers view MD programs as a learning process in which they are provided with opportunities to combine their own knowledge and experience with the knowledge and experience of others to acquire new knowledge [7]. Motivation theories have been widely applied to adult learning participation theories (Wang, Wang, 2006). The important role of managers' motivation in their development process is highlighted by the extent to which their jobs provide them with learning opportunities which in turn paves the way for their marketability in the job market. Therefore, the presence of learning opportunities in organizations influences the learning ability of individual managers and that of the whole company [15]. Also, MD has been said to have mandates including creating improvements in organizational performance resulting from managers' mastery in conducting their roles effectively and also encouraging managers to build their career portfolios [4]. The latter mandate highlights the significance of managers' incentives in pursuing MD activities.

There are many instances in which organizations are not effective in allocating resources to their MD activities [16]. For instance, allocating money as a scarce resource in almost all companies to be devoted to MD might be perceived as a perk rather than a priority [17]. In a study conducted among companies in Ireland, buy-in from senior management and corporate support were found as two strong rationales in companies which invest in MD activities [4]. A problem addressed by managers in Norwegian companies about their MD practices was that of support from superiors and subordinates [7]. This demonstrates that management 
support is a critical factor in the allocation of organizational resources to MD activities. The HRM context of an organization is supposed to be a determinant factor of the MD processes adopted by the organization [18]. MD has been viewed as the system of personnel practices to ensure adequate availability of competent and motivated managers [2]. Considering human resource management strategies as a component of MD activities, findings of another study revealed that 9 out of 13 organizations stated that they recruited some formal processes for identification of high-potential managers as candidates to be funded for pursuing some sort of MD activities [4]. Organizationally-sponsored training makes up a type of learning and development activities [19] and as a component of MD is concerned with needs assessment, training content and methods, etc [2].

MD effectiveness is defined as the extent to which MD programs achieve their expected outcomes. One way to evaluate the effectiveness of MD activities is to rely on perceived effectiveness expressed by managers [20]. Supposedly, effective MD results in improved managerial knowledge and skills [17]. MD can be viewed as a means of improving managerial skills including financial, marketing, human resources, strategy, strategic management, change management and generic management skills [21].

All of the above-mentioned variables act as different components of a unique MD system in order to develop leading managers in ever-changing organizational contexts (Figure 1).

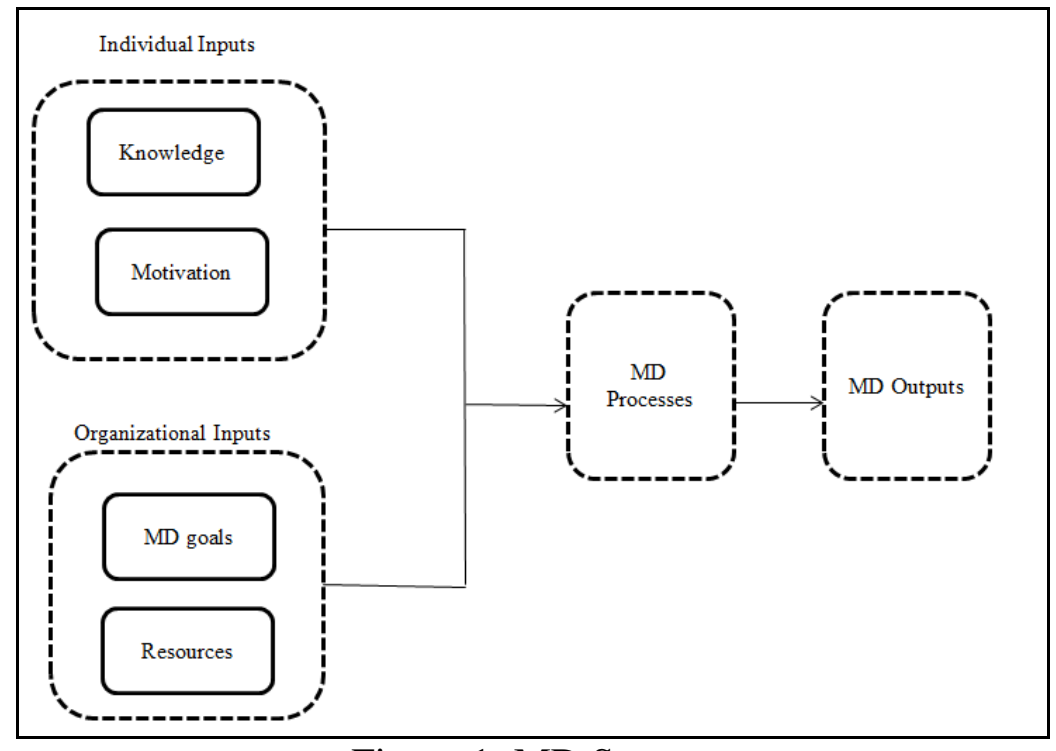

Figure 1: MD System

\section{Research Methodology and Findings}

In order to examine MD status among insurance companies, a self-administered questionnaire was used and insurance managers as key informants were selected 
as respondents. MD is measured using a 47-item questionnaire developed by researchers using a scale ranging from 1 (does not exist at all) to 5 (excellent).

In this paper we focus on establishing the contemporary nature of MD in Iran through the appraisal of the status of managerial knowledge and motivation, human resources management, organizational resources, training system and managers' skills. We also sought to examine whether managers' views regarding the status of MD in insurance companies differ in terms of their managerial position.

We also examined whether managerial knowledge, managers' motivation, organizational resources allocated to MD activities, HRM strategies and training system in organizations impacted the development of managerial skills.

The questionnaire is verified prior to distribution among respondents, using the survey on 20 experts. Before the experts begin to confirm/reject the questionnaires, the definitions of the 47 questions and the reasons of the investigation are clearly explained to each of them. In order to confirm the consistency of the experts' opinions on the corresponding results, the binomial test is used to test the null hypothesis of 'There are no differences among experts' opinions'. Each expert indicated his/her opinion by selecting 'Agree' (1) or 'Disagree' (0) for each item. The test proportion is assumed as 0.50 denoting that at least 50 percent of the experts are expected to agree on the questionnaire. The results showed that the experts mostly agreed on the proposed questionnaire with a confidence level of 0.95. SPSS package (version 15) is used to analyze the collected data.

Out of 400 questionnaires distributed among managers in different managerial positions in 2 public and 8 private insurance companies in Iran, 305 were collected back, representing a response rate of 76 percent.

After data collection and analysis, initial findings are derived and the average and standard deviation of the variables were calculated as illustrated in Table 1. The reliability of variables measuring various aspects of MD was studied by analyzing the inter-item correlations with Cronbach's alpha. The resulting values indicated that the variables employed measured the same latent constructs.

As could be seen in table 1, all research variables have their mean values in the range of 2.5 to 3 which indicate that they are lower than the cut point of 3 . Also, their standard deviations are smaller than 1 which shows a rather less-dispersed distribution of variable scores around their mean. However, managers' knowledge and motivation have the highest mean; training system has the least dispersion around its mean and human resource management has the largest dispersion around its mean.

One- sample T-test was conducted to test if the sample mean is significantly different from the population mean (Table 2). In this case, we assume the population mean to be equal to the specified value of 3 (cut point); therefore, the result of the T-test shows that insurance managers' knowledge is not equal to the assumed amount of $3(\mathrm{t}=-4.113 ; \mathrm{df}=304$; $\mathrm{sig}=0.000)$. Considering the sample mean of managers' knowledge (2.75) in table 1 , it is evident that the sample mean 
is significantly different from the assumed value of 3 and it's lower than that. The same is true about managers' motivation. The results of T-test conducted on this variable represents that the sample score on motivation is significantly different from $3(\mathrm{t}=-4.113 ; \mathrm{df}=304 ; \mathrm{sig}=0.002)$ and it's smaller than 3 (mean $=2.75$; SD $=0.80)$. Also, organizational resources score below the assumed average of 3 (Mean $=2.69, \mathrm{SD}=0.69)$ which is statistically significant $(\mathrm{t}=4.50, \mathrm{df}=304, \mathrm{sig}$ $=0.00$ ). The mean score for training systems of insurance companies under our study scored below the assumed average of 3 (mean $=2.17, \mathrm{SD}=0.63$ ) which also statistically significant $(\mathrm{t}=13.47, \mathrm{df}=304$, sig $=0.00)$. In this research, the human resources management of insurance companies averaged below 3 (mean $=$ $2.53, \mathrm{SD}=0.86)$ which is also statistically significant $(\mathrm{t}=-5.97, \mathrm{df}=304$, $\mathrm{sig}=$ $0.00)$.

Table1: Descriptive statistics of research variables

\begin{tabular}{|c|c|c|}
\hline & Mean & SD \\
\hline Knowledge & 2.75 & 0.75 \\
\hline Motivation & 2.75 & 0.80 \\
\hline Resources & 2.69 & 0.69 \\
\hline Training & 2.17 & 0.63 \\
\hline HRM & 2.53 & 0.86 \\
\hline Skills & 2.61 & 0.76 \\
\hline
\end{tabular}

MD activities are interpreted differently at different organizational levels (Cullen, Turnbull, 2005). Therefore, by using ANOVA post hoc tests, we studied if the means of variables in different management groups varied from each other. Based on this, all the mean differences between the groups turned out to be insignificant at the 0.05 level. So different management groups were considered be on the same path regarding the status of MD in insurance industry.

Table 2: Mean comparisons

\begin{tabular}{|c|c|c|c|c|c|c|}
\hline & \multicolumn{6}{|c|}{ Cut point $=3$} \\
\hline & \multirow[t]{2}{*}{$\mathbf{t}$} & \multirow[t]{2}{*}{ df } & \multirow[t]{2}{*}{ Sig. } & \multirow[t]{2}{*}{$\begin{array}{c}\text { Mean } \\
\text { difference }\end{array}$} & \multicolumn{2}{|c|}{$\begin{array}{l}95 \% \text { confidence } \\
\text { interval }\end{array}$} \\
\hline & & & & & Lower & Upper \\
\hline Knowledge & -4.113 & 304 & 0.00 & -0.321 & -0.475 & -0.166 \\
\hline Motivation & -3.18 & 304 & 0.002 & -0.24 & -0.39 & -0.091 \\
\hline Resources & 4.50 & 304 & 0.00 & -0.300 & -0.43 & -0.16 \\
\hline Training & 13.47 & 304 & 0.00 & -0.82 & -0.94 & -0.70 \\
\hline HRM & -5.97 & 304 & 0.00 & -0.45 & -0.61 & -0.30 \\
\hline Skills & -5.30 & 304 & 0.00 & -0.38 & -0.53 & -0.24 \\
\hline
\end{tabular}


Table 3: Regression analysis

\begin{tabular}{|c|c|c|}
\hline \multicolumn{3}{|c|}{ Managerial skills } \\
\hline \multicolumn{3}{|c|}{$\mathrm{R}^{2}=0.80$} \\
\hline Knowledge & 0.34 & $\mathrm{P}>0.05$ \\
\hline Motivation & 0.39 & $\mathrm{P}<0.05$ \\
\hline Resources & 0.16 & $\mathrm{P}>0.05$ \\
\hline HRM & 0.43 & $\mathrm{P}<0.05$ \\
\hline Training system & -0.15 & $\mathrm{P}>0.05$ \\
\hline
\end{tabular}

$\mathrm{R}^{2}$ indicates that the proportion of variability in managerial skills accounted by managerial knowledge, motivation, resources, HRM and training system is 0.80 . However, results of multiple regression analysis represent that among all the variables, only motivation and HRM strategies are significantly associated with managerial skills, taking into account that HRM strategies explains the most variance in managerial skills in insurance industry.

\section{Conclusion}

Survival for insurance companies in Iran in the current changing micro and macro business climate is an uphill struggle. Overcoming large-scale changes which they are presently confronted by is a not an easy task. In this study, our goal was to capture and describe how managers in insurance companies perceive their experience with different aspects of MD. Following Goleman (1999) suggestions regarding assessment of managers' level of readiness by themselves [22], this research is an attempt to capture managers' perception of MD current status in insurance industry of Iran. Goleman found that only 20 percent of participating managers who attended MD programs willingly participated and the remaining 80 percent participated just because they were expected to do so by their organizations. Therefore, one way of increasing MD effectiveness is to provide these initiatives at the request of managers who are ready to learn. This is possible through increasing managers' awareness of the current status of MD. Based on the findings of this paper, the current status of MD in the organizations under study was below average which indicated that decision-makers in these organizations should be cognizant about improving the status of these variables. Also, the only two variables that impacted managerial skills were managers' motivation to learn and also HRM strategies in organizations. Among the variables studied, HRM strategies had the highest impact on the development of managerial skills. Therefore, managers in insurance industry of Iran and other countries with similar circumstances should be aware of the significance of HRM strategies in the development of their management capital. It is noteworthy to mention that managers are not necessarily developed through large investments in training and 
development activities; however, one way to develop them is through developing appropriate HRM strategies.

It is recommended that future researchers study the applicability of this systematic model in different contexts and countries to validate its generalizability. Also, based on previous literature, it is possible to add other components to the model.

\section{References}

[1] A. Margherita, G. Secundo, Density, diversity, openness and speed: Is management development aligned?, Journal of Management Development, (2007), 28(10), 933-944.

[2] J. Cullen, S. Turnbull, A meta-review of the management development literature, Human Resource Development Review, (2005), 4(3), 335-355.

[3] P. Brown, The evolving role of strategic management development, Journal of Management development, (2005), 24(3), 209-222.

[4] M. O'Connor, J. Mangan, J. Cullen, Management development in Ireland: Justifying the investment, Journal of Management development, (2006), 25(4), 325-349.

[5] J. Wang, G.G. Wang. Participation in management development in a transitioning context: A case of China, Human Resource Quarterly, (2006), 17(4), 443-473.

[6] N. Heraty, M.J. Morley, Management Development in Ireland: the new organizational wealth?, Journal of Management Development, (2003), 22(1), 60-82.

[7] B. Espedal, B. Management and leadership development in Norway: Discrepancies between talk and action, Advances in Human Resources Development, (2004), 6 (4), 470-485.

[8] P.Jansen, M. Van Der Velde, W. Mul W. (2001). A typology of management development, Journal of Management Development, (2001), 2(20), pp. 106120.

[9] J. Paawe, R. Williams, Management development revisited, Journal of Management Development, (2001), 20(2), 106-120.

[10] C. Mahieu, Management development in Royal Dutch /Shell, Journal of Management development, (2001), 20 (2), 121-130.

[11] A. Klarsfeld, C. Mabey, Management development in Europe: Do national models persist?, European Management Journal, (2004), 6(22), 649-658.

[12] S. Watson, Conceptual model for analyzing management development in hospitality industry: A UK perspective, International Journal of Hospitality Management, (2008), 27, 414-425.

[13] T.T. Baldwin, T.T., M.Y. Patgett, Management development: A review and commentary, in C.L. Cooper, I.T. Robertson, (Eds), Key Reviews in Managerial Psychology, Wiley, New York, NY, (1994), 270-320. 
[14] C. Gray, C. Mabey, Management Development: Key differences between small and large businesses in Europe, International Small Business Journal, (2005), 23(5), 467-485.

[15] L. Van der Sluis-Den Dikken, L.H. Hoeksema, The palette of management development, Journal of Management Development, (2001), 20(2), 168-179.

[16] P.S. Kirkbride, Management development: In search of a new role, Journal of Management Development, (2003), 22 (2), 171-180.

[17] B. D'Netto, F. Bakas, P. Bordia, Predictors of management development effectiveness: An Australian perspective, International Journal of Training and Development, (2008), 12(1), 2-23.

[18] C. Mabey, Mapping management development practice, Journal of Management Studies, (2002), 39(8), 1139-1160.

[19] K.D. Kuznia, J.S.J.Kerno, A. Gilley, The correlates and influences of careerrelated continuous learning: Implications for management professional, Performance Improvement Quarterly, (2010), 22(4), 7-31.

[20] M. Luoma, Managers' perceptions of strategic role of management development, Journal of Management Development, (2005), 24(7), 645-665.

[21] N. Fuller-love, Management Development in Small Firms, International Journal of Management Reviews, (2006), 8(16), 175-190.

[22] D. Goleman, Working with Emotional Intelligence, London: Bloomsbury Publishing, (1999), 121-122. 